\title{
Rapid assessment of bovine spongiform encephalopathy prion inactivation by heat treatment in yellow grease produced in the industrial manufacturing process of meat and bone meals
}

\author{
Miyako Yoshioka ${ }^{1,2}$, Yuichi Matsuura', Hiroyuki Okada', Noriko Shimozaki', Tomoaki Yamamura', \\ Yuichi Murayama ${ }^{1 *}$, Takashi Yokoyama ${ }^{1}$ and Shirou Mohri ${ }^{1}$
}

\begin{abstract}
Background: Prions, infectious agents associated with transmissible spongiform encephalopathy, are primarily composed of the misfolded and pathogenic form ( $\mathrm{PrP}^{\mathrm{SC}}$ ) of the host-encoded prion protein. Because PrPSc retains infectivity after undergoing routine sterilizing processes, the cause of bovine spongiform encephalopathy (BSE) outbreaks are suspected to be feeding cattle meat and bone meals (MBMs) contaminated with the prion. To assess the validity of prion inactivation by heat treatment in yellow grease, which is produced in the industrial manufacturing process of MBMs, we pooled, homogenized, and heat treated the spinal cords of BSE-infected cows under various experimental conditions.
\end{abstract}

Results: Prion inactivation was analyzed quantitatively in terms of the infectivity and $\operatorname{PrP}{ }^{S c}$ of the treated samples. Following treatment at $140^{\circ} \mathrm{C}$ for $1 \mathrm{~h}$, infectivity was reduced to $1 / 35$ of that of the untreated samples. Treatment at $180^{\circ} \mathrm{C}$ for $3 \mathrm{~h}$ was required to reduce infectivity. However, $\operatorname{PrP}^{\mathrm{SC}}$ was detected in all heat-treated samples by using the protein misfolding cyclic amplification (PMCA) technique, which amplifies PrPSc in vitro. Quantitative analysis of the inactivation efficiency of BSE PrPSC was possible with the introduction of the PMCA ${ }_{50}$, which is the dilution ratio of $10 \%$ homogenate needed to yield $50 \%$ positivity for $\mathrm{PrP}^{\mathrm{SC}}$ in amplified samples.

Conclusions: $\log \mathrm{PMCA}_{50}$ exhibited a strong linear correlation with the transmission rate in the bioassay; infectivity was no longer detected when the $\log P M C A_{50}$ of the inoculated sample was reduced to 1.75 . The quantitative PMCA assay may be useful for safety evaluation for recycling and effective utilization of MBMs as an organic resource.

Keywords: Prion inactivation, Bovine spongiform encephalopathy, Meat and bone meal, Yellow grease, Infectivity, Protein misfolding cyclic amplification

\footnotetext{
* Correspondence: ymura@affrc.go.jp

${ }^{1}$ Prion Disease Research Center, National Institute of Animal Health, 3-1-5

Kannondai, Tsukuba, Ibaraki 305-0856, Japan

Full list of author information is available at the end of the article
} 


\section{Background}

Transmissible spongiform encephalopathies (TSEs), including scrapie in sheep and goats, chronic wasting disease (CWD) in deer and elk, bovine spongiform encephalopathy (BSE) in cattle, and Creutzfeldt-Jakob disease (CJD) in humans, are infectious and fatal neurodegenerative diseases [1]. Proteinaceous infectious agents called prions are thought to be responsible for TSEs, which are characterized by the accumulation of the pathogenic form of prion protein $\left(\mathrm{PrP}^{\mathrm{Sc}}\right)$ in the nervous tissues of infected subjects $[2,3] \cdot \operatorname{PrP}^{\mathrm{Sc}}$ is a conformational isoform of the normal cellular prion protein $\left(\mathrm{PrP}^{\mathrm{C}}\right)$, which is rich in beta-sheet structures, insoluble in mild detergents, and resistant to protease digestion $[4,5]$.

Because prions retain infectivity after undergoing routine sterilization processes [6], contaminated meat and bone meals (MBMs) are suspected to be the source of BSE infection $[7,8]$. MBMs are manufactured through a multi-step process involving the crushing of carcasses in a pre-breaker, heating at $120^{\circ} \mathrm{C}-140^{\circ} \mathrm{C}$ in yellow grease (lower-quality grades of tallow) in a cooker, and degreasing from solid material by an oil separator. To determine BSE prion inactivation during the manufacturing process of MBMs, industrial processes were replicated on a pilot scale by using BSE-infected brains, and the infectivity of processed materials in each step was investigated in detail [9]. However, in reality, processing conditions for MBMs differ among rendering houses producing commercial MBMs. Since the efficiency of prion inactivation could be influenced by various factors such as treatment temperature, time, steam pressure in the cooker, size, water and fat contents of carcasses [10-13], it is difficult to identify the risks attributable to specific processing conditions. Furthermore, $\operatorname{PrP}^{\mathrm{Sc}}$ retained in the manufacturing process of MBMs remains to be elucidated.

The governments of many countries prohibited the feeding of bovine MBMs following the feeding ban on MBMs in the United Kingdom. A prion detection method with high sensitivity and high accuracy must be developed so that MBMs can be used safely in the future. In addition, BSE prion is more resistant to physical and chemical treatments than are scrapie and CJD prions [14]. Therefore, experiments using BSE-infected materials are essential for the assessment of BSE prion inactivation as they can be considered a worst case among prions. In recent years, it has become possible to perform in vitro amplification of $\mathrm{PrP}^{\mathrm{Sc}}$ derived from various animals [15-21] by using protein misfolding cyclic amplification (PMCA) [22]. We developed an ultrasensitive method for $\mathrm{BSE} \mathrm{PrP}^{\mathrm{Sc}}$ detection using potassium dextran sulfate (DSP) [20]. The PMCA technique can also be used to quantitatively assess scrapie $\operatorname{PrP}^{\mathrm{Sc}}$ [23-25], and our PMCA method can be applied as an effective test for the assessment of prion inactivation by monitoring residual BSE
$\operatorname{PrP}^{\mathrm{Sc}}$ [26]. In the present study, we investigated efficiency of BSE prion inactivation following heat treatment in yellow grease by bioassay and quantitative PMCA.

\section{Results}

Infectivity of heat-treated homogenates

Long-term follow-up confirmed infectivity in the mice intracerebrally inoculated with up to a $10^{-5}$ dilution of the $10 \%$ homogenate of the pooled spinal cords (Table 1 ). $\mathrm{PrP}^{\mathrm{Sc}}$ accumulation was confirmed in the brains of the diseased mice by western blotting and histopathological analysis (data not shown). The infectious titer of the homogenate was estimated to be $10^{6.7} \mathrm{LD}_{50}$ per gram. A strong linear correlation $(r=0.99)$ between the incubation times and dilution ratios of the inoculated homogenate was observed in mice inoculated with up to a $10^{-3}$ dilution. Some mice inoculated with $10^{-4}$ and $10^{-5}$ diluted samples developed the disease after similar prolonged survival times (735 or 736 days). In the extreme dilution range, lower rate of transmission and prolonged incubation time are generally observed in the mice intracerebrally inoculated with prion-infected brain homogenates. Since $\mathrm{PrP}^{\mathrm{Sc}}$ tends to aggregate, these phenomena may be due to the near-absence of $\mathrm{PrP}^{\mathrm{Sc}}$ which would have been almost completely diluted out.

Table 2 shows the effect of various heat treatments in yellow grease on the BSE-infected spinal cord homogenates. All mice inoculated with samples treated at $140^{\circ} \mathrm{C}$ for $1 \mathrm{~h}$ died after an average of 304 days. The infectivity was reduced to approximately $1 / 35(\log$ reduction $=1.54)$ following the heat treatment. When the samples subjected to temperatures above $140^{\circ} \mathrm{C}$ were used, $100 \%\left(180^{\circ} \mathrm{C}\right.$ for $1 \mathrm{~h})$ and $67 \%\left(160^{\circ} \mathrm{C}\right.$ for $\left.1 \mathrm{~h}\right)$ of the mice developed the disease after prolonged average survival times. Regarding the treatments for $3 \mathrm{~h}$, infectivity was still detected in some mice inoculated with the samples treated at $140^{\circ} \mathrm{C}$ or $160^{\circ} \mathrm{C}$. Because the incubation times of these diseased mice were beyond the range of application of the regression line obtained using the titrated BSE-infected homogenates, the log reduction of infectivity in each sample was estimated to be more than 3.0. Meanwhile, mice inoculated with samples treated at $180^{\circ} \mathrm{C}$ for $3 \mathrm{~h}$ did not exhibit disease onset 790 days after inoculation.

\section{PrP $^{\text {Sc }}$ detection by PMCA}

Figure 1a illustrates the results of the amplification of the samples subjected to the grease-heating method. No $\operatorname{PrP}^{\mathrm{Sc}}$ signals were detected in the heat-treated samples by western blotting before amplification (data not shown). After one round of amplification, $\operatorname{PrP} \mathrm{P}^{\mathrm{Sc}}$ signals were detected in the samples treated at $140^{\circ} \mathrm{C}-180^{\circ} \mathrm{C}$ for $1 \mathrm{~h}$ and at $140^{\circ} \mathrm{C}$ for $3 \mathrm{~h}$. $\operatorname{PrP}^{\mathrm{Sc}}$ signals were also detected in both duplicate samples treated at $160^{\circ} \mathrm{C}$ and $180^{\circ} \mathrm{C}$ for $3 \mathrm{~h}$ after two or three rounds of amplification. In the 


\begin{tabular}{l}
$\begin{array}{l}\text { Table } 1 \text { Mean incubation time of TgBoPrP mice following } \\
\text { intracerebral inoculation of titrated bovine spongiform } \\
\text { encephalopathy (BSE)-infected spinal cord homogenate }\end{array}$ \\
\begin{tabular}{lll} 
10\% Homogenate & $\begin{array}{l}\text { Transmission rate } \\
\text { (diseased/total) }\end{array}$ & \multicolumn{1}{c}{$\begin{array}{l}\text { Mean incubation } \\
\text { time } \pm \text { SD (days) }\end{array}$} \\
\hline $10^{0}$ & $100 \%(7 / 7)$ & $242 \pm 14$ \\
$10^{-1}$ & $100 \%(7 / 7)$ & $279 \pm 12$ \\
$10^{-2}$ & $100 \%(5 / 5)$ & $322 \pm 42$ \\
$10^{-3}$ & $100 \%(6 / 6)$ & $367 \pm 53$ \\
$10^{-4}$ & $33 \%(2 / 6)$ & $736,736,>790$ \\
$10^{-5}$ & $17 \%(1 / 6)$ & $735,>790$ \\
$10^{-6}$ & $0 \%(0 / 6)$ & $>790$
\end{tabular} \\
\hline
\end{tabular}

samples treated at $180^{\circ} \mathrm{C}$ for $3 \mathrm{~h}$, trace amounts of $\operatorname{Pr} \mathrm{P}^{\mathrm{Sc}}$ remained after the treatment, although infectivity was not detected in the bioassay.

\section{Quantitative analysis of $\operatorname{PrP}^{\mathrm{Sc}}$}

Figure 1b shows the results of the amplification of each diluted sample of untreated BSE-infected spinal cord homogenate. $\operatorname{PrP}^{\mathrm{Sc}}$ present in $10^{-7}$ dilution of the infected homogenate was detected in all tubes after three rounds of amplification. $\mathrm{PrP}^{\mathrm{Sc}}$ signals were detected in three of the $10^{-8}$ and one of the $10^{-9}$ dilutions after three rounds of amplification. However, no additional tubes became positive for $\mathrm{PrP}^{\mathrm{Sc}}$ in these dilutions after four rounds of amplification. No signals were detected in the more extreme dilution ranges even after four rounds of amplification. Thus, the $\mathrm{PMCA}_{50}$ of the $10 \%$ homogenate was calculated to be $10^{8.5}$ units on the basis of the results obtained from the fourth round of amplification.

To evaluate the $\mathrm{PrP}^{\mathrm{Sc}}$ inactivation efficiency of each heat treatment, we estimated the $\mathrm{PMCA}_{50}$ from the results obtained at the fourth round of amplification of serial 10fold dilutions of heat-treated samples. Serial PMCA was sufficiently sensitive to detect $\operatorname{PrP}^{\mathrm{Sc}}$ in these diluted samples (Figure 2). The log reduction of $\mathrm{PMCA}_{50}$ values of the heat-treated samples are shown in Table 2. Regarding the treatments for $1 \mathrm{~h}, \operatorname{PrP}^{\mathrm{Sc}}$ inactivation appeared to be most efficient in the samples treated at $160^{\circ} \mathrm{C}$. This finding is concordant with the observations of partial transmission of infectivity (67\%) in the mice inoculated with this sample and prolonged incubation times of the diseased mice. Log $\mathrm{PMCA}_{50}$ decreased with extended heat treatment time: although $180^{\circ} \mathrm{C}$ for $3 \mathrm{~h}$ was the most effective treatment, it was unable to completely inactivate the proportion of $\mathrm{PrP}^{\mathrm{Sc}}$ that is amplifiable by serial PMCA.

Figure 3 shows the relationships between the transmission rate in the bioassay and the $\log \mathrm{PMCA}_{50}$ values of the inoculated samples. A strong linear correlation $(\mathrm{r}=$ 0.97) was observed between the $\log \mathrm{PMCA}_{50}$ values and transmission rate. When the log $\mathrm{PMCA}_{50}$ exceeded 5.25, the transmission rate in the bioassay reached $100 \%$ as observed in the mice inoculated with samples treated at $140^{\circ} \mathrm{C}$ or $180^{\circ} \mathrm{h}$ for $1 \mathrm{~h}$. Infectivity was not detected in the mice when the $\log \mathrm{PMCA}_{50}$ of the inoculated sample was reduced to 1.75 .

\section{Discussion}

In this study, BSE prion inactivation was analyzed quantitatively in terms of infectivity and the $\mathrm{PrP}^{\mathrm{Sc}}$ contents of the samples after heat treatment in yellow grease. Following treatment at $140^{\circ} \mathrm{C}$ for $1 \mathrm{~h}$, which is the heat treatment condition generally used for carcasses in rendering houses in Japan, the infectivity of the BSEinfected spinal cord homogenate was reduced to at most $1 / 35$ of that of the untreated control samples; furthermore, $\operatorname{PrP}^{\mathrm{Sc}}$ retained its capability for in vitro propagation. Because carcasses are usually heat treated in closed cookers, prions are affected by the steam pressure from the water contained in the carcass. If a sufficient amount of water is present in the carcass, prion inactivation may proceed more efficiently in the cooker than under atmospheric pressure. However, some degree of BSE infectivity was still detected after autoclaving at $133^{\circ} \mathrm{C}$ in spiked raw materials with high infectivity levels [26]. Furthermore, the precise effects of high-pressure steam on carcasses submerged in yellow grease are not known. Therefore, high-risk materials such as brains and spinal cord should be excluded from the rendering process for effective inactivation of BSE prion.

Table 2 Effects of various heat treatments in yellow grease on BSE-infected spinal cord homogenates

\begin{tabular}{llllll}
\hline Temperature & Time (h) & $\begin{array}{l}\text { Transmission rate } \\
\text { (diseased/total) }\end{array}$ & $\begin{array}{l}\text { Mean incubation } \\
\text { time } \pm \text { SD (days) }\end{array}$ & $\begin{array}{l}\text { Log reduction } \\
\text { of infectivity }\end{array}$ & $\begin{array}{l}\text { Log reduction } \\
\text { of PMCA }\end{array}$ \\
\hline $140^{\circ} \mathrm{C}$ & 1 & $100 \%(6 / 6)$ & $304 \pm 13^{*, \neq}$, & 1.54 & 2.75 \\
& 3 & $83 \%(5 / 6)$ & $382 \pm 64,>790$ & $>3.0$ & 4.0 \\
$160^{\circ} \mathrm{C}$ & 1 & $67 \%(4 / 6)$ & $471 \pm 80^{*,+},>790$ & $>3.0$ & 3.5 \\
$180^{\circ} \mathrm{C}$ & 3 & $17 \%(1 / 6)$ & $514,>790$ & $>3.0$ & 6.0 \\
& 1 & $100 \%(6 / 6)$ & $380 \pm 25^{\dagger, \neq}$ & $>3.0$ & 3.25 \\
\hline
\end{tabular}

${ }^{*},+, \neq$ Significant differences $\left({ }^{*}: p<0.01 ; \dagger, \ddagger: p<0.05\right)$ were observed among mice with respect to the mean incubation times as indicated by identical superscript character. 


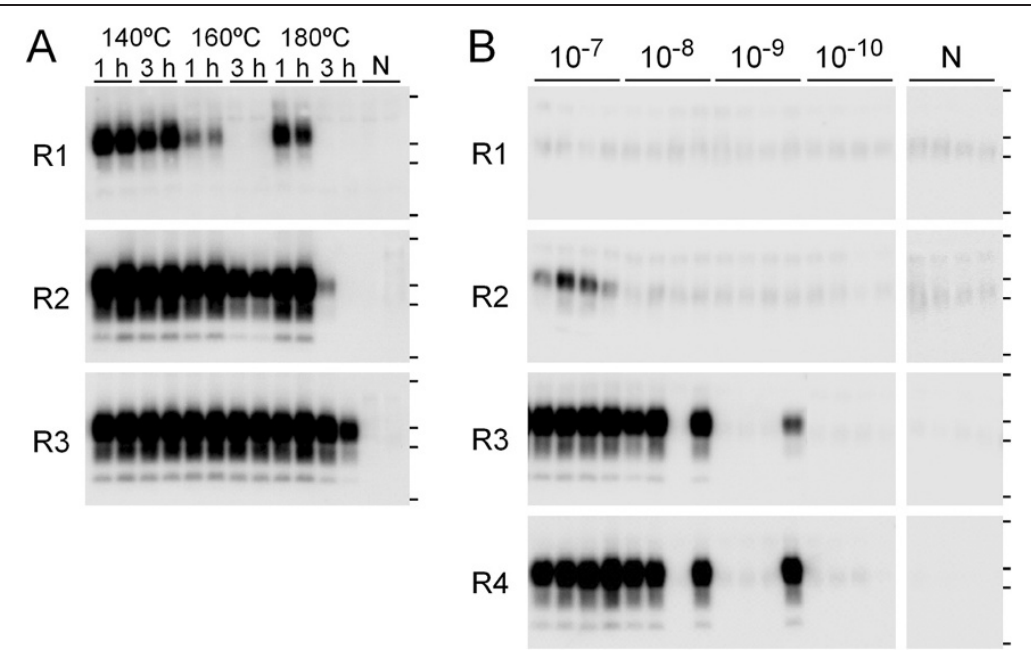

Figure 1 Detection of bovine spongiform encephalopathy (BSE) PrP ${ }^{S c}$ by serial potassium dextran sulfate-protein misfolding cyclic amplification. (A) Homogenates (10\%) of BSE-infected spinal cords treated in yellow grease at $140^{\circ} \mathrm{C}-180^{\circ} \mathrm{C}$ for 1 or $3 \mathrm{~h}$ were diluted $10^{-1}$ with the $\operatorname{PrP}^{C}$ substrate and amplified by serial PMCA. Duplicate samples were analyzed after each round (R1-R4) of amplification by western blotting after digestion with proteinase $\mathrm{K}$. The lanes labeled " $\mathrm{N}$ " are samples in which only the PrPC substrate was treated in the same manner. Horizontal lines indicate the positions of molecular-weight markers corresponding to 37, 25, 20, and $15 \mathrm{kDa}$. (B) Homogenates (10\%) of the heat-untreated BSE-infected spinal cords were diluted $10^{-7}$ to $10^{-10}$ with the PrP ${ }^{C}$ substrate and amplified in four tubes by serial PMCA.

We previously examined residual infectivity and $\operatorname{PrP}^{\mathrm{Sc}}$ after heat treatment of scrapie-infected hamster brains under various experimental conditions [27]. The PMCA results were concordant with bioassay results. However, BSE $\operatorname{PrP}^{\mathrm{Sc}}$ was detected in the samples treated at $180^{\circ} \mathrm{C}$ for $3 \mathrm{~h}$, although infectivity was not detected in the bioassay. There are several possible explanations for this discrepancy between infectivity and $\operatorname{PrP}^{\mathrm{Sc}}$ occurrence. For example, BSE $\operatorname{PrP}^{\mathrm{Sc}}$ might contain various forms of $\mathrm{PrP}^{\mathrm{Sc}}$ with different amplification properties and infectivity, and a PMCA-compatible form of $\mathrm{PrP}^{\mathrm{Sc}}$ with low or no infectivity might predominate after heat treatment and be maintained over other forms throughout the amplification process. However, in the present study, the $\log \mathrm{PMCA}_{50}$ values were strongly correlated with the transmission rate in the bioassay (Figure 3), suggesting that such PMCAcompatible but less-infectious $\operatorname{PrP}^{\mathrm{Sc}}$ was not selectively amplified in vitro.

In our previous paper, we demonstrated our amplification system was highly sensitive and accurate, and no spontaneous generation of $\operatorname{PrP}^{\mathrm{Sc}}$ was observed in the amplification of various kind of samples derived from

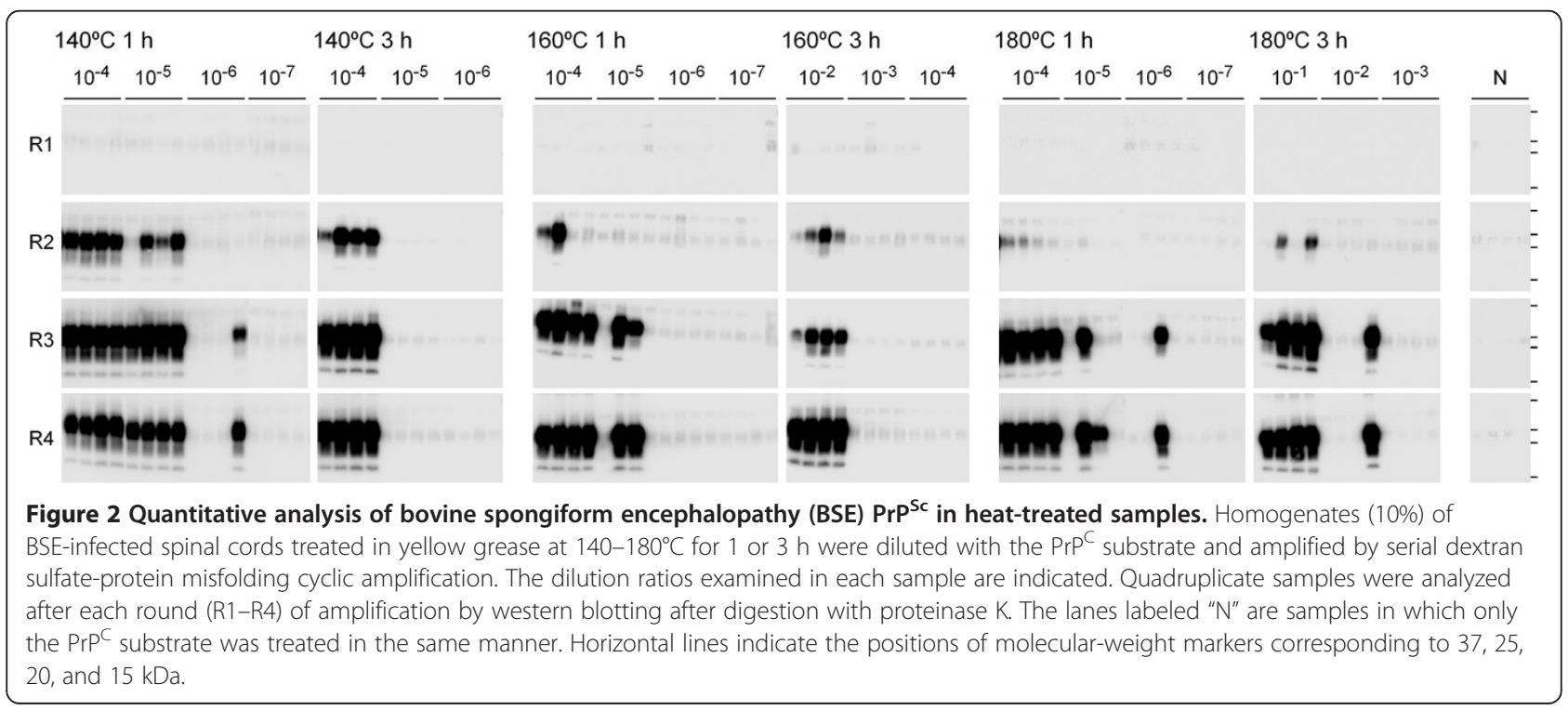




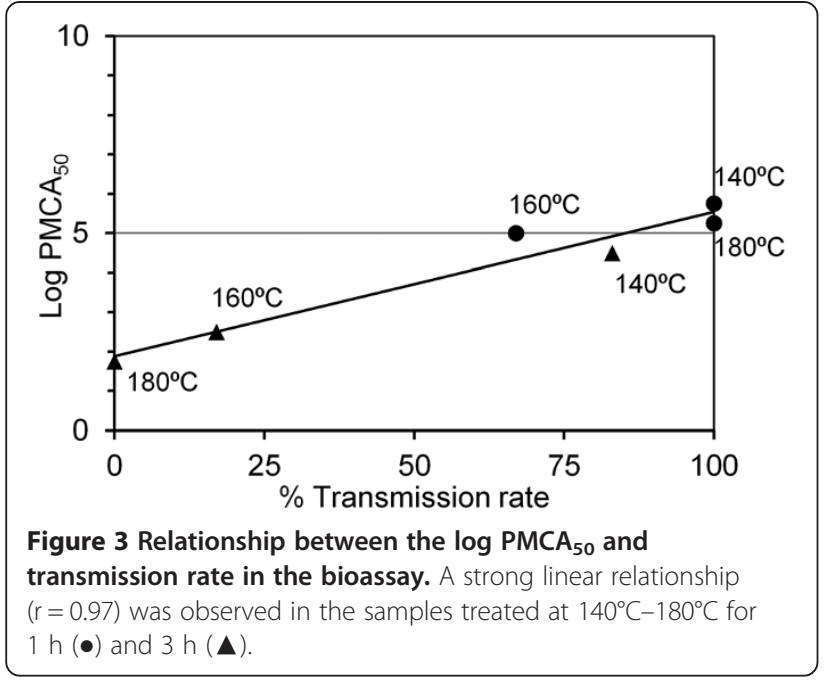

uninfected animals [20]. Determination of $\mathrm{PMCA}_{50}$ based on quadruplicate amplification was also done in our previous study [26], and we confirmed that similar PMCA $_{50}$ values (around $10^{11}$ per gram) were obtained in two independent studies. In the present study, the $\mathrm{PMCA}_{50}$ of the BSE-infected spinal cords was estimated to be $10^{11.6}$ per gram, which is approximately 80,000 fold greater than the corresponding intracerebral $\mathrm{LD}_{50}$ per gram $\left(10^{6.7}\right)$ determined by the bioassay. The $\mathrm{PMCA}_{50} / \mathrm{LD}_{50}$ per gram of BSE prion was considerably higher than those of scrapie prion strains (160-4000 fold) [25]. If this ratio reflects the number of $\mathrm{PrP}^{\mathrm{Sc}}$ particles that compose an infectious unit of prions, more $\mathrm{PrP}^{\mathrm{Sc}}$ particles might participate in an infectious unit of BSE prions; moreover, such a large mass of $\operatorname{PrP}^{\mathrm{Sc}}$ particles might be processed into several smaller ones with lower infectivity in vivo.

Alternatively, $\mathrm{PrP}^{\mathrm{Sc}}$ accumulation might proceed in animals inoculated with $\mathrm{PrP}^{\mathrm{Sc}}$ when the $\mathrm{PrP}^{\mathrm{Sc}}$ concentration is below a specific cut-off, but the animals might not develop the disease within their lifetimes. Actually, clinically asymptomatic infections are known as the subclinical infection stage [28-30]. In the present study, we examined $\mathrm{PrP}^{\mathrm{Sc}}$ in brains of asymptomatic mice inoculated with titrated BSE-infected homogenate, and $\operatorname{PrP}^{\mathrm{Sc}}$ was found at various levels in four of five mice inoculated with $10^{-6}$ dilution of the infected homogenate (Figure 4). Therefore, pathogenicity might be detected by serial transmission in animals as in the case of serial PMCA. If so, the detection sensitivity of the bioassay used in the present study may not be sufficiently high for proper safety evaluation, because ecycling of BSEinfected bovine tissues possibly augments the concentration of $\mathrm{PrP}^{\mathrm{Sc}}$ in commercial MBMs if the carcasses contain infinitesimal amounts of prion.
Another aspect of heat treatment in yellow grease is that higher-temperature treatments do not necessarily inactivate BSE prion more effectively. In the case of heat treatment for $1 \mathrm{~h}$, the results of both the bioassay and PMCA indicate that BSE prion inactivation proceeded more effectively with treatment at $160^{\circ} \mathrm{C}$ rather than at $180^{\circ} \mathrm{C}$. Samples treated at $180^{\circ} \mathrm{C}$ were dark brown, suggesting that the surface was scorched during treatment. In such high-temperature conditions, thermal conduction may be inhibited by scorching of the sample periphery, consequently requiring longer treatment time to reach thermal equilibrium in the sample. Extension of the treatment time to $3 \mathrm{~h}$ was actually necessary for the loss of infectivity. However, further studies are needed to confirm the above possibility.

\section{Conclusions}

In this study, we demonstrated that heat treatment at $180^{\circ} \mathrm{C}$ for $3 \mathrm{~h}$ is required for the loss of infectivity of BSE prion in grease heating in our experimental conditions. Furthermore, BSE $\operatorname{PrP}^{\mathrm{SC}}$ retains amplification ability even after such a treatment. The inactivation efficiency of BSE $\mathrm{PrP}^{\mathrm{Sc}}$ could be quantitatively analyzed with the introduction of the $\mathrm{PMCA}_{50}$, which is strongly correlated with the transmission rate in the bioassay. The serial PMCA technique is more practical and less time consuming than bioassays, and may be applicable for monitoring residual

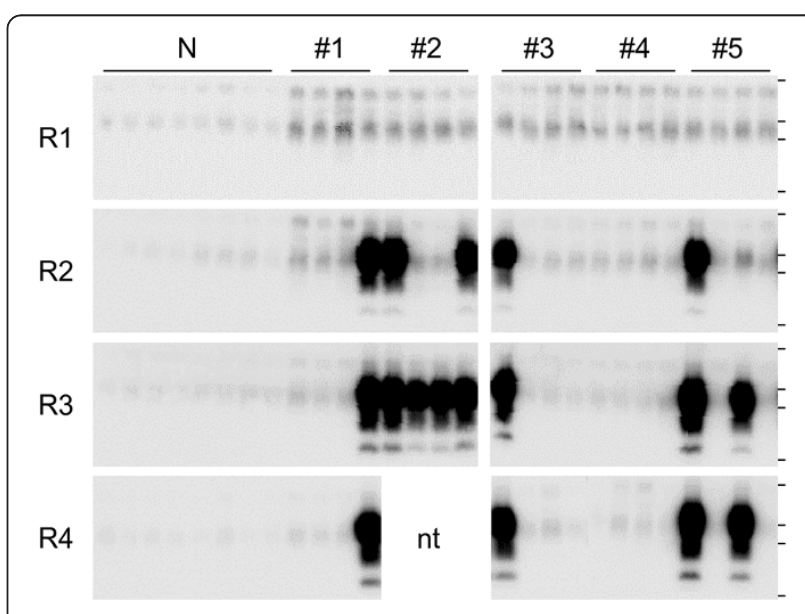

Figure 4 Detection of $\mathrm{PrP}^{\mathrm{Sc}}$ in brains of asymptomatic mice. A $10 \%$ brain homogenate from five (\#1-\#5) of six asymptomatic mice inoculated with $10^{-6}$ dilution of infected homogenate (Table 1) was prepared, and amplified by serial PMCA. Quadruplicate samples were analyzed after each round (R1-R4) of amplification by western blotting after digestion with proteinase K. One (\#1 and \#3), two (\#5) and four (\#2) of the quadruplicate samples were found to be positive for $\operatorname{PrP}^{S c}$ after three or four rounds of amplification. No PrP $\mathrm{P}^{\mathrm{Sc}}$ signal was detected in \#4 mouse. The eight lanes labeled " $\mathrm{N}$ " are samples in which only the PrPC substrate was treated in the same manner. Horizontal lines indicate the positions of molecular-weight markers corresponding to $37,25,20$, and $15 \mathrm{kDa}$. nt: not tested. 
$\mathrm{PrP}^{\mathrm{Sc}}$ in the other steps of the manufacturing of MBMs and useful for safety evaluation for recycling and effective utilization of MBMs as an organic resource.

\section{Methods}

\section{Experimental heat treatment procedure}

All animal experiments were approved by the Animal Care and Use Committee of the National Institute of Animal Health (approval IDs: 450 and 08-008) in accordance with the Guidelines for Animal Transmissible Spongiform Encephalopathy Experiments of the Ministry of Agriculture, Forestry, and Fisheries of Japan. Spinal cords were obtained from four cows experimentally inoculated with BSE at the terminal stage of the disease. The infected materials were pooled and homogenized using a blender. Pure homogenate $(0.5 \mathrm{~g})$ was placed on a strip of aluminum foil $(2 \mathrm{~cm} \times 2 \mathrm{~cm})$ and stored at $80^{\circ} \mathrm{C}$ until further use. For use, the homogenate with the aluminum foil was thawed at room temperature and then immersed in $15 \mathrm{~mL}$ yellow grease preheated to $140^{\circ} \mathrm{C}, 160^{\circ} \mathrm{C}$, or $180^{\circ} \mathrm{C}$ in a ceramic crucible by using an electric heating device (ND-M11, Nissin Rika, Tokyo, Japan). The yellow grease used was obtained from a rendering house in Japan. The crucible was covered, and a thermosensor was inserted through a hole in the cover to monitor the temperature of the yellow grease. The yellow grease was, then, kept for 1 or $3 \mathrm{~h}$ at the desired temperature. The homogenate sample firmly adhered to the surface of aluminum foil and was not broken into pieces during the heat treatment. After the treatment, the homogenate with the aluminum foil was removed from the yellow grease with tweezers and placed on a paper towel for absorption of the excess yellow grease. The weights of the homogenates were reduced to 60 $70 \%$ of their original weights. The resultant materials were thoroughly crushed with a mortar, and suspended in PBS at $10 \%(\mathrm{w} / \mathrm{v})$. Insoluble materials were separated by brief centrifugation, and aqueous fraction was stored at $-80^{\circ} \mathrm{C}$ until further use.

\section{Bioassay}

Infectivity titer using transgenic mice overexpressing bovine $\operatorname{PrP}^{C}$ is generally $100-1000$ times higher than that using cows. Therefore, more accurate estimation of BSE infectivity is able to be conducted by using such mice. The heat-treated samples were injected intracerebrally into six $\mathrm{Tg}(\mathrm{BoPrP}) 4092 \mathrm{HOZ} / \mathrm{Prnp}^{\mathrm{O} / 0}$ (TgBoPrP) transgenic mice $(20 \mu \mathrm{L}$ per mouse) overexpressing bovine $\operatorname{PrP}^{\mathrm{C}}$ [31]. To determine the infectivity titer, serial 10fold dilutions of the $10 \%$ homogenate of the untreated spinal cords were prepared in PBS and injected intracerebrally into five to seven $\mathrm{TgBoPrP}$ mice $(20 \mu \mathrm{L}$ per mouse). After inoculation, the mice were evaluated daily for signs of infection. The lethal dose $\left(\mathrm{LD}_{50}\right)$ was determined according to the $50 \%$ endpoint calculation method. Mean incubation times of the diseased mice were analyzed by one-way ANOVA and Tukey's multiple comparison test.

\section{PMCA}

Bovine $\operatorname{PrP}^{\mathrm{Sc}}$ was amplified as described previously [20]. Briefly, the brains of $\mathrm{TgBoPrP}$ transgenic mice and $\operatorname{PrP}$ knockout $\left(\mathrm{PrP}^{0 / 0}\right)$ mice were homogenized separately in PBS containing $1 \%$ Triton $\mathrm{X}-100$ and $4 \mathrm{~m} \mathrm{~mol} \mathrm{~L} \mathrm{~L}^{-1}$ EDTA. After centrifugation at $4500 \times g$ for $5 \mathrm{~min}$, the supernatants were mixed in $\operatorname{PrP}^{0 / 0} / \operatorname{TgBoPrP}(5: 1)$. A mixture containing $0.5 \%$ DSP was used as the $\operatorname{PrP}^{\mathrm{C}}$ substrate for PMCA.

The 10\% homogenates of heat-treated samples were mixed at 1:9 with the $\operatorname{PrP}^{C}$ substrate (total volume, $100 \mu \mathrm{L})$ in electron beam-irradiated polystyrene tubes. Amplification was performed in duplicate with a fully automatic cross-ultrasonic protein-activating apparatus (Elestein 070-CPR, Elekon Science, Chiba, Japan), which has a capacity to generate high ultrasonic power $(700 \mathrm{~W})$. PMCA amplification was performed by 40 cycles of sonication (3-s pulse oscillations repeated 5 times at 1-s intervals), followed by incubation at $37^{\circ} \mathrm{C}$ for $1 \mathrm{~h}$ with agitation. For serial PMCA, 1:5 dilution of the PMCA product and subsequent amplification was repeated twice.

To evaluate the inactivation efficiency of BSE $\operatorname{PrP}^{\mathrm{Sc}}$ by heat treatment, the $\mathrm{PMCA}_{50}$, which is the dilution ratio of the $10 \%$ homogenate needed to yield $50 \% \mathrm{PrP}^{\mathrm{Sc}}$ positivity for amplified samples, was determined. Serial 10 -fold dilutions of the $10 \%$ homogenate of the heat-treated and untreated samples were prepared and mixed 1:9 with the $\operatorname{PrP}^{\mathrm{C}}$ substrate (total volume, $80 \mu \mathrm{L}$ ) and amplified in electron beam-irradiated eight-strip polystyrene tubes (07696, Elekon Science). Amplification was performed in quadruplicate using 40 cycles of sonication (pulse oscillation for $5 \mathrm{~s}$, repeated 5 times at 1-s intervals), followed by incubation at $37^{\circ} \mathrm{C}$ for $1 \mathrm{~h}$ with agitation. For serial PMCA, 1:5 dilution of the amplified product and subsequent amplification was repeated 3 times. The $\mathrm{PMCA}_{50}$ was estimated from the results of the fourth round of amplification by using the $50 \%$ endpoint calculation method.

\section{Western blotting}

The amplified samples $(10 \mu \mathrm{L})$ were mixed with $10 \mu \mathrm{L}$ proteinase $\mathrm{K}$ solution $\left(100 \mu \mathrm{g} \mathrm{mL} \mathrm{m}^{-1}\right)$ and incubated at $37^{\circ} \mathrm{C}$ for $1 \mathrm{~h}$. The digested samples were mixed with $20 \mu \mathrm{L} 2 \times$ SDS sample buffer and incubated at $100^{\circ} \mathrm{C}$ for $5 \mathrm{~min}$. The samples were separated by SDS-PAGE and transferred onto a polyvinylidene fluoride membrane (Millipore, Bedford, MA). After the membrane was blocked, it was incubated for 30 min with a horseradish peroxidase (HRP)-conjugated T2 monoclonal antibody 
[32]. After washing, the blotted membrane was developed using the Luminata Forte Western HRP Substrate (Millipore) according to the manufacturer's instructions. Chemiluminescence signals were analyzed with a Light Capture System (Atto, Tokyo Japan).

\section{Histopathological analysis}

The left hemispheres of the brains were fixed in $10 \%$ buffered formalin for neuropathological analysis. Coronal brain sections were immersed in $98 \%$ formic acid to reduce infectivity and embedded in paraffin wax. Sections ( $4 \mu \mathrm{m}$ thick) were cut and stained with hematoxylin and eosin, and analyzed immunehistochemically as described previously [20].

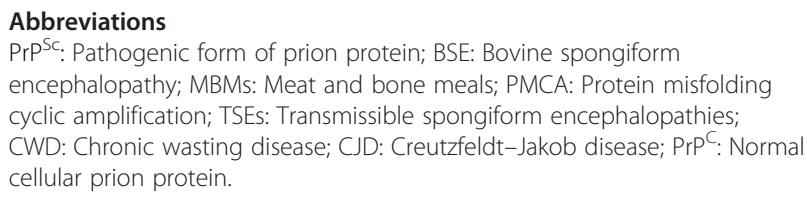

\section{Competing interests}

The authors declare that they have no competing interests.

\section{Authors' contributions}

MY and YM (Murayama) designed and prepared the manuscript. MY, YM (Matsuura), HO and YM (Murayama) performed the experiments. NS and TY helped to perform the experiments. TY and SM supervised the study. All authors have read and approved the final manuscript.

\section{Acknowledgments}

We wish to thank the animal caretakers of the Prion Disease Research Center of the National Institute of Animal Health for their assistance. This study was funded by a grant from the Bovine Spongiform Encephalopathy Control Project of the Ministry of Agriculture, Forestry, and Fisheries of Japan.

\section{Author details}

'Prion Disease Research Center, National Institute of Animal Health, 3-1-5 Kannondai, Tsukuba, Ibaraki 305-0856, Japan. ${ }^{2}$ Research Area of Pathology and Pathophysiology, National Institute of Animal Health, 3-1-5 Kannondai, Tsukuba, Ibaraki 305-0856, Japan.

Received: 25 March 2013 Accepted: 3 July 2013

Published: 9 July 2013

\section{References}

1. Collinge J: Prion diseases of humans and animals: their causes and molecular basis. Annu Rev Neurosci 2001, 24:519-550.

2. Prusiner SB: Molecular biology of prion disease. Science 1991, 252(5012):1515-1522.

3. Prusiner SB: Prions. Proc Natl Acad Sci USA 1998, 95(23):13363-13383.

4. Caughey BW, Dong A, Bhat KS, Ernst D, Hayes SF, Caughey WS: Secondary structure analysis of the scrapie-associated protein $\operatorname{PrP} 27-30$ in water by infrared spectroscopy. Biochemistry 1991, 30(31):7672-7680

5. Pan KM, Baldwin M, Nguyen J, Gasset M, Serban A, Groth D, Mehlhorn I, Huang Z, Fletterick RJ, Cohen FE, et al: Conversion of a-helics into $\beta$-sheets features in the formation of the scrapie prion proteins. Proc Nat Acad Sci USA 1993, 90(23):10962-10966.

6. Taylor DM: Resistance of transmissible spongiform encephalopathy agents to decontamination. In Prions, A Challenge for Science, Medicine and Public Health System. Edited by Rabenau HF, Ciantl J, Doerr HW. Basel: Karger; 2001:58-67.

7. Wilesmith JW, Wells GA, Cranwell MP, Ryan JB: Bovine spongiform encephalopathy: epidemiological studies. Vet Rec 1988, 123(25):638-644

8. Butler D: Statistics suggest BSE now 'Europe-wide'. Nature 1996, 382(6586):4
9. Taylor DM: Inactivation of the bovine spongiform encephalopathy agent by rendering procedures. Vet Rec 1995, 137(24):605-610.

10. Taylor DM: Inactivation of prions by physical and chemical means. $J$ Hosp Infect 1999, 43(Suppl 1):S69-S76.

11. Taylor DM, Fernie K, McConnell I, Steele PJ: Observations on thermostable subpopulations of the unconventional agents that cause transmissible degenerative encephalopathies. Vet Microbio/ 1998, 64(1):33-38.

12. Schreuder BEK, Geertsma RE, van Keulen $\amalg$, van Asten JA, Enthoven $P$, Oberthür RC, de Koeijer AA, Osterhaus AD: Studies on the efficacy of hyperbaric rendering procedures in inactivation bovine spongiform encephalopathy (BSE) and scrapie agents. Vet Rec 1998, 142(18):474-480

13. Muller H, Stitz L, Wille H, Prusiner SB, Riesner D: Influence of water, fat, glycerol on the mechanism of thermal prion inactivation. J Biol Chem 2007, 282(49):35855-35867.

14. Giles K, Glidden DV, Beckwith R, Seoanes R, Peretz D, DeArmond SJ, Prusiner SB: Resistance of bovine spongiform encephalopathy (BSE) prions to inactivation. PLoS Pathog 2008, 4(11):e1000206.

15. Saá P, Castilla J, Soto C: Ultra-efficient replication of infectious prions by automated protein misfolding cyclic amplification. J Biol Chem 2006, 281(46):35245-35252.

16. Murayama $Y$, Yoshioka $M$, Yokoyama $T$, Iwamaru $Y$, Imamura $M$, Masujin $K$ Yoshiba S, Mohri S: Efficient in vitro amplification of a mouse-adapted scrapie prion protein. Neurosci Lett 2007, 413(3):270-273.

17. Kurt TD, Perrott MR, Wilusz CJ, Wilusz J, Supattapone S, Telling GC, Zabel MD, Hoover EA: Efficient in vitro amplification of chronic wasting disease PrP ${ }^{\text {RES }}$. J Virol 2007, 81(17):9605-9608.

18. Thorne $L$, Terry $L A$ : In vitro amplification of $\operatorname{PrP}^{\mathrm{Sc}}$ derived from the brain and blood of sheep infected with scrapie. J Gen Virol 2008, 89(12):3177-3184.

19. Jones M, Peden AH, Prowse CV, Gröner A, Manson JC, Turner ML, Ironside JW, MacGregor IR, Head MW: In vitro amplification and detection of variant Creutzfeldt-Jakob disease PrP ${ }^{\text {Sc }}$. J Pathol 2007, 213(1):21-26.

20. Murayama Y, Yoshioka M, Masujin K, Okada H, Iwamaru Y, Imamura M, Matsuura Y, Fukuda S, Onoe S, Yokoyama T, et al: Sulfated dextrans enhance in vitro amplification of bovine spongiform encephalopathy $\mathrm{PrP}^{\mathrm{SC}}$ and enable ultrasensitive detection of bovine PrP ${ }^{\mathrm{Sc}}$. PLOS One 2010, 5(10):e13152.

21. Yokoyama T, Takeuchi A, Yamamoto M, Kitamoto T, Ironside JW, Morita M: Heparin enhances the cell-protein misfolding cyclic amplification efficiency of variant Creutzfeldt-Jakob disease. Neurosci Lett 2011 , 498(2):119-123.

22. Saborio GP, Permanne B, Soto C: Sensitive detection of pathological prion protein by cyclic amplification of protein misfolding. Nature 2001, 411(6839):810-813.

23. Chen B, Morales R, Barria MA, Soto C: Estimating prion concentration in fluids and tissues by quantitative PMCA. Nat Meth 2010, 7(7):519-520.

24. Pritzkow S, Wagenführ K, Daus ML, Boerner S, Lemmer K, Thomzig A Mielke M, Beekes M: Quantitative detection and biological propagation of scrapie seeding activity in vitro facilitate use of prions as model pathogens for disinfection. PLoS One 2011, 6(5):e20384.

25. Makarava N, Savtchenko R, Alexeeva I, Rohwer RG, Baskakov IV: Fast and ultrasensitive method for quantitating prion infectivity titre. Nat Commun 2012, 3:741.

26. Matsuura Y, Ishikawa Y, Bo X, Murayama Y, Yokoyama T, Somerville RA, Kitamoto T, Mohri S: Quantitative analysis of wet-heat inactivation in bovine spongiform encephalopathy. Biochem Biophys Res Commun 2013, 432(1):86-91.

27. Murayama Y, Yoshioka M, Horii H, Takata M, Yokoyama T, Sudo T, Sato K, Shinagawa M, Mohri S: Protein misfolding cyclic amplification as a rapid test for assessment of prion inactivation. Biochem Biophys Res Commun 2006, 348(2):758-762.

28. Race $R$, Chesebro B: Scrapie infectivity found in resistant species. Nature 1998, 392(6678):770.

29. Hill AF, Joiner $S$, Linehan J, Desbruslais $M$, Lantos PL, Collinge J: Species-barrier-independent prion replication in apparently resistant species. Proc Natl Acad Sci USA 2000, 97(18):10248-10253.

30. Race R, Raines A, Raymond GJ, Caughey B, Chesebro B: Long-term subclinical carrier state precedes scrapie replication and adaptation in a resistant species: analogies to bovine spongiform encephalopathy and variant Creutzfeldt-Jakob disease in humans. J Virol 2001, 75(21):10106-10112 
31. Scott MR, Safar J, Telling G, Nguyen O, Groth D, Torchia M, Koehler R, Tremblay $\mathrm{P}$, Walther $\mathrm{D}$, Cohen FE, et al: Identification of a prion protein epitope modulating transmission of bovine spongiform encephalopathy prions to transgenic mice. Proc Natl Acad Sci USA 1997, 94(26):14279-14284.

32. Hayashi HK, Yokoyama T, Takata M, Iwamaru Y, Imamura M, Ushiki YK, Shinagawa M: The N-terminal cleavage site of $\mathrm{PrP}^{\mathrm{Sc}}$ from BSE differs from that of PrP ${ }^{\mathrm{Sc}}$ from scrapie. Biochem Biophys Res Commun 2005, 328(4):1024-1027.

doi:10.1186/1746-6148-9-134

Cite this article as: Yoshioka et al:: Rapid assessment of bovine spongiform encephalopathy prion inactivation by heat treatment in yellow grease produced in the industrial manufacturing process of meat and bone meals. BMC Veterinary Research 2013 9:134.

\section{Submit your next manuscript to BioMed Central and take full advantage of:}

- Convenient online submission

- Thorough peer review

- No space constraints or color figure charges

- Immediate publication on acceptance

- Inclusion in PubMed, CAS, Scopus and Google Scholar

- Research which is freely available for redistribution 